International JOURNAL OF MultidisciplinaRy Research AND ANALysis

ISSN(print): 2643-9840, ISSN(online): 2643-9875

Volume 04 Issue 10 October 2021

DOI: 10.47191/ijmra/v4-i10-10, Impact Factor: 6.072

Page No.- 1411-1417

\title{
Implementation of Automation System in Production in Hydroponic Green Feed
}

\section{P.I. Kalandarov ${ }^{1}$, D.A. Abdullayeva ${ }^{2}$,M. S. Yusupov ${ }^{3}$}

${ }^{1}$ Doctor of Technical Sciences, Professor Tashkent Institute of Irrigation and Agricultural Mechanization Engineers

${ }^{2}$ Tashkent Institute of Irrigation and Agricultural Mechanization Engineers

${ }^{3}$ Tashkent Institute of Irrigation and Agricultural Mechanization Engineers

ABSTRACT: The article deals with theproblems of improving the production of fodder and the development of a new method of hydroponic green feed. The use of automation elements using humidity and temperature sensors to regulate the irrigation process, measuring soil moisture, outdoor temperature, as well as additional luminosity is shown. The possibility of using abundantdevices to control the technological processisshown. A program has been developed. Amma for control of the technological process of growing green feed, in the programming language for controllers, describes proportionally integraldifferential law of regulation to ensure high accuracy of temperature maintenance, giving the method of setting PID coefficients.

KEYWORDS: green food, hydroponics, humidity, temperature, sensor, controller, PID regulator, automation scheme, automated system.

\section{INTRODUCTION}

In the conditions of Uzbekistan, the issue of producing hydroponic green fodder is the most pressing issue in agriculture, including animal husbandry. The solution to this problem, in turn, is aimed at finding solutions to several existing problems. First of all, if there is a technology for preparing the method of hydroponics, then secondly, we are talking about the introduction of this technology into an automated system to facilitate human labor and increase labor productivity [1].

The solution to this issue would find its solution if it were focused on the following, including: the introduction of modern technologies in the production of hydroponic green feed for livestock, characterized by its high calorie protein content and ensuring the development of its high-quality varieties and the creation of appropriate climatic conditions for storage throughout the year. This, in turn, leads to a qualitative innovative analysis of the available composition ofproteins, in particular to the correction of the energy deficiency of protein and nutritious feeds, which in our country will allow the movement of genetic potentiala [2].

This means that even when developing pet food, there is a need to improve feed production in the industry.

\section{MATERIALS AND METHODS}

In order to attract a wide range of foreign investments in the village of Koriktom, Yangiarik district, Khorezm region, in 2019, a foreign enterprise LLC "Engineering of Energy-Saving Technologies" was created. The main task of the organization is to grow green feed for livestock, poultry and fish hydroponic method [3].

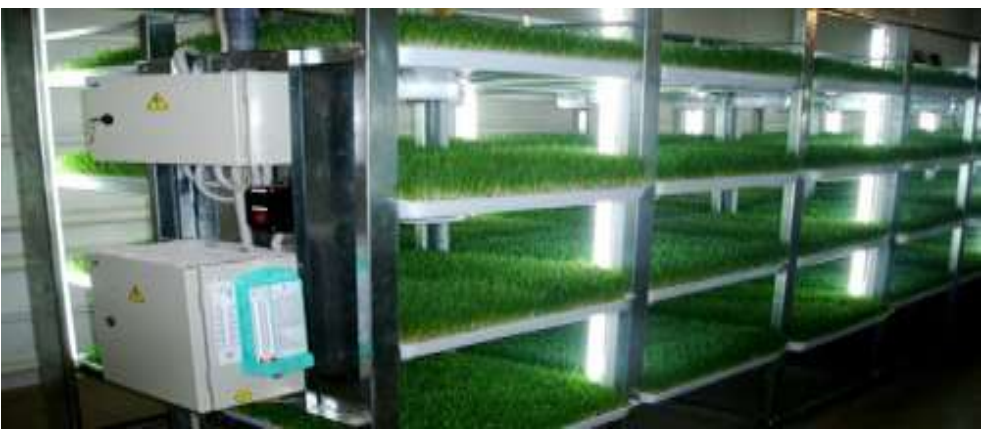

Fig.1. General view of production of hydroponic green feeds using automation 


\section{Implementation of Automation System in Production in Hydroponic Green Feed}

The hydroponic method of growing green fodder is a method of growing plants without soil, in which the plant receives from the solution all the necessary nutrients in the right quantities and exact proportions (which is almost impossible to implement with soil cultivation). The method of hydroponics is based on the study of the root system of the plant, and specifically how the plant is nourished. As a result, hydroponics allows you to regulate the growing conditions of plants - to create a diet for the root system, which fully meets the needs of plants for nutrients. Using hydroponic technology indoors, we can also regulate the concentration of carbon dioxide in the air, which is favorable for photosynthesis, regulate air humidity, air temperature, and the duration and intensity of light.

It's no secret that in the winter and spring seasons, the availability of livestock with vitamin nutrients decreases. In this case, hydroponic green feed is one of the most convenient nutrients, which means that its production is the most pressing problem.

Well, let's try to answer the question of what green food is grown by this methodof gidroponics and how it differs from other feed feeds.

It is not an exaggeration to say that green hydroponic feed is an alternative to feed and other feeds. Green hydroponic feed is one of the old methods that have survived in our ancestors, this method passes from generation to generation.Its difference fromsumalak is that the purified seeds are cleaned in special devices and take whole seeds, irradiated for 10 minutes with special mercury bactericidal lamps, that is, the contaminated grain is thoroughly washed in clean water. Special solutions are added to the composition of the water that kill harmful substances and purify them. Hydroponics products are a methodthat allows the plant to grow without roots [4].

Asa materialfor hydroponic feed,you can use various seedsand,for example: wheat,barley, corn, etc. [5].

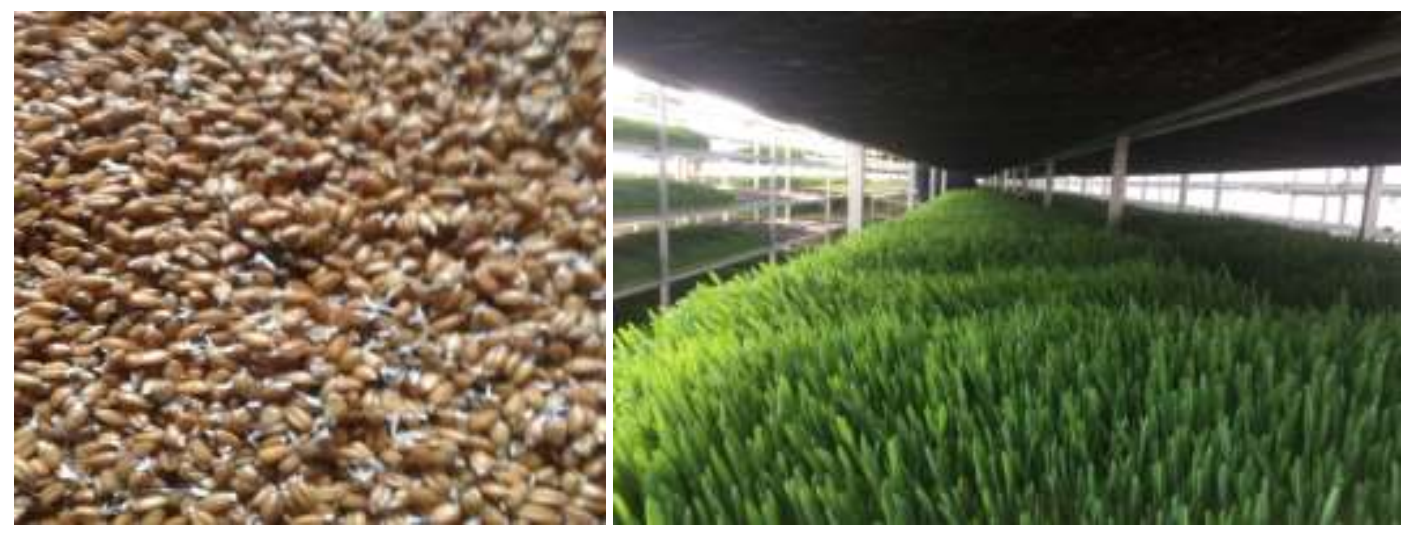

Fig. 2. Type of germination of wheat and finished hydroponic green feed

If you compare the prices of feed, then you can distinguish that gof putronic green feed is 6-8 times cheaper than grass, 5-6 times cheaper than mixed fodder and 3 times cheaper than wheat. Green feeds contain the necessary nutrients and vitamins, they are well absorbed and impregnated,are environmentally friendly products, the production of which is simple and economical $[6]$.

Hydroponic nutrition is of great biological importance. It contains $28.93 \%$ protein, $96.73 \%$ fat, in addition to biologically active substances (carotene and chlorophyll), compared to other nutrients [7].

\section{OUTCOMES}

According to the results of research and comparison with open ground, hydroponic cultivation allowed us tofree upland for other purposes, totherum of this cost for waterand other investments decreasedand elm several times. The absence of preservatives, thermal, mechanical treatment, as well as the addition of chemicals ensures complete environmental purity of the product. Due to the fact that the seeds do not germinate in the open ground, they are not susceptible to attacks by pests, insects. Accordingly, there is no need to treat them with special substances that have a bad effect on the appearance, nutritional value of greenery. Metered watering of the roots prevents theirdecay. With the help of lamps significantly increased thegrowth of chlorophyll in plants. Its economic efficiency is proved by much lower costs for land, labor resources, fuel, use of agricultural machinery. In the presence of vitamins, chemical composition, hydroponic feeds are ahead of cereals, grasses.

Discussing this topic, it is more important in addition to cooking and the technology used to study the system of its preparation using an automated system using automation elements. 


\section{Implementation of Automation System in Production in Hydroponic Green Feed}

Within the framework of this article, the method and results of the implementation of the automation system in the preparation of a green nutrient in the conditions of the Republic of Uzbekistan are presented.

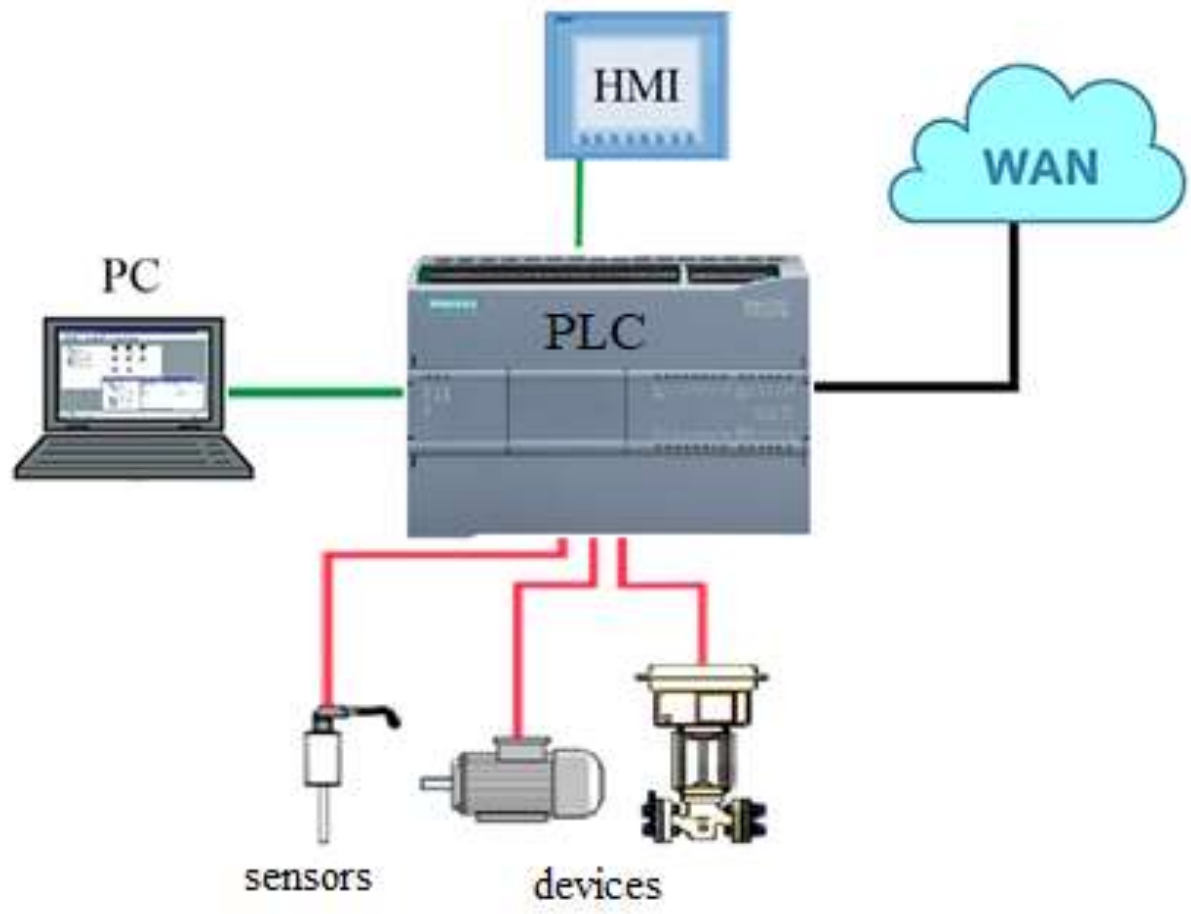

Fig. 3. - PLC and device connection diagram

The above diagram shows the presence of sensors to obtain information about the state of the technological process and PLC, which develops the effects of controlling the technological process of growing green feeds, $\mathrm{HMI}$ and PC control panels, as well as the ability to connect to the Internet, which allows remote control in the ONline mode, and through the web page tsu [ 8].

When controlling the process of growing green feeds, we can perform HMI (Humun Machine Interfase) through the operator panel (Fig.3).

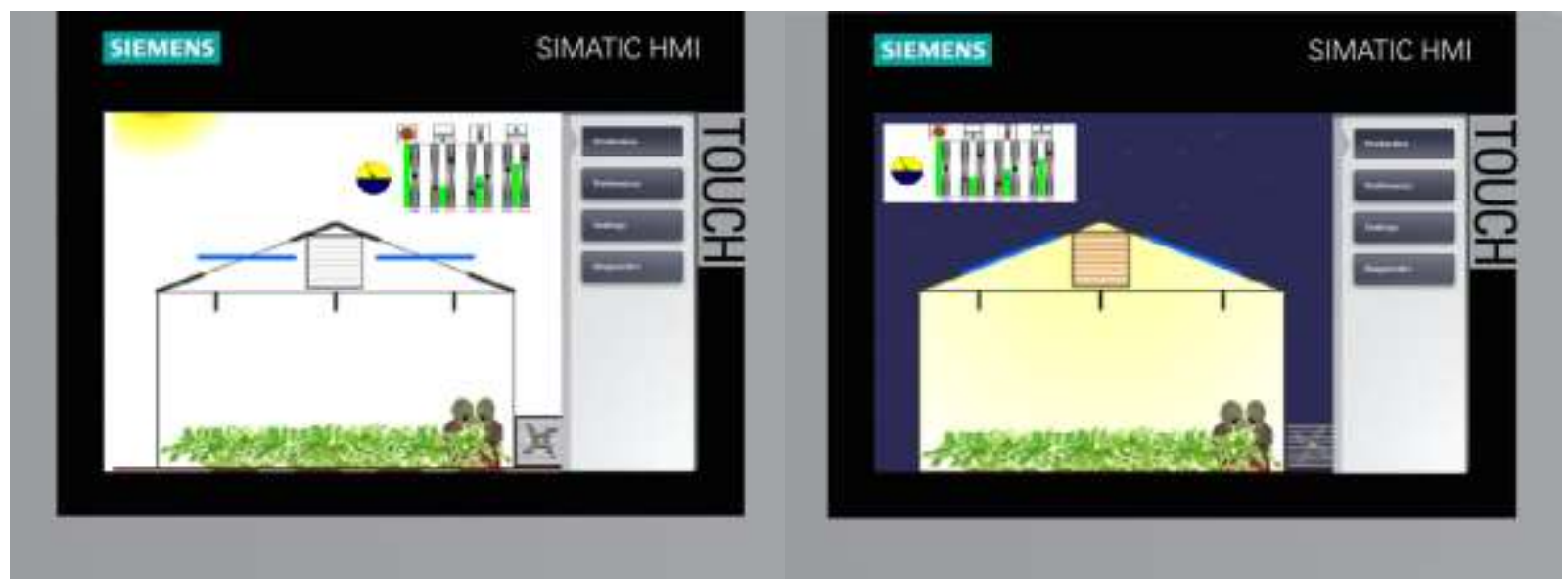

Fig 4. HMI Operator Panel Inspection Process

Mobile devices, that is, a personal smartphone, can also be used to control the technological process using the touch of the operator. This can be done in accordance with the following two schemes (Fig.5,6) [9]. In the first case, a device is used that generates a Wi-Fi Local network (wifi router), and the mobile device controls the technological process by connecting to this network and entering a special Login, password. In the second case, it is necessary to connect to the Internet. In both cases, the operator performs this control by entering the Internet browser on his smartphone. 


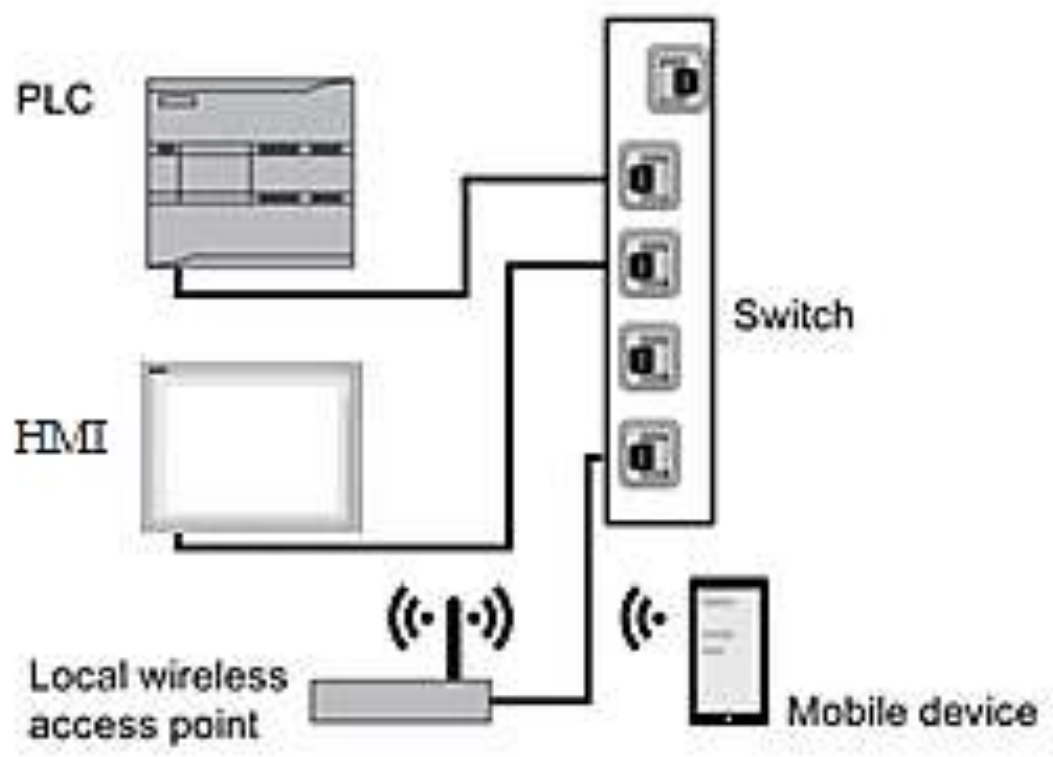

Fig. 5. Diagram of using a local Wi-Fi network when managing using a mobile device

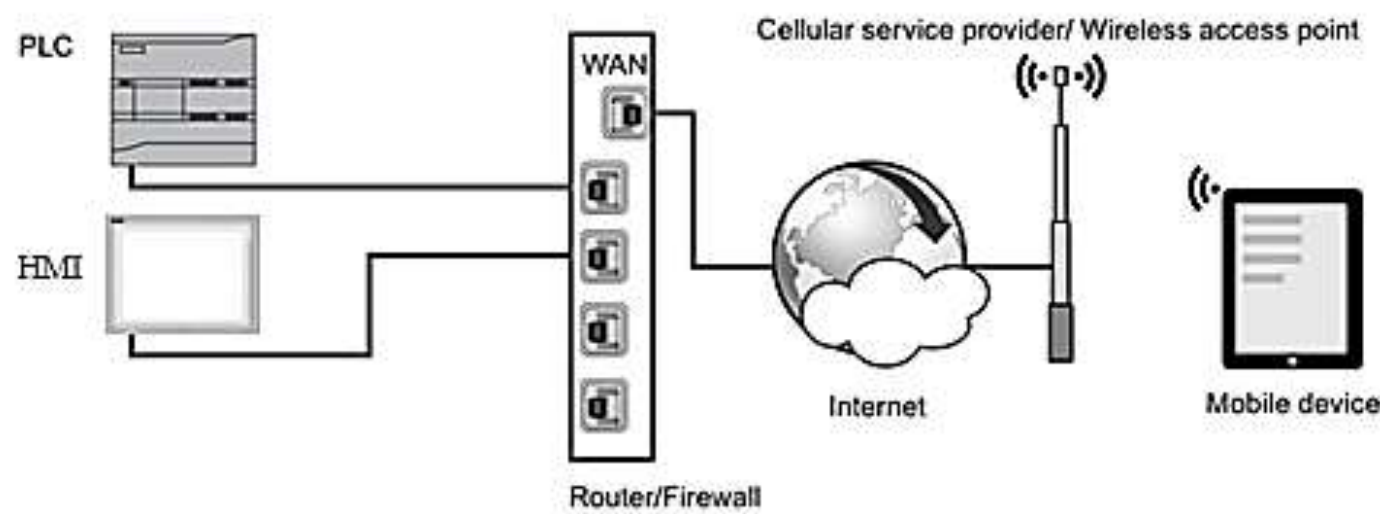

Fig. 6. Diagram of Internet usage in mobile device management

The construction of the control scheme is carried out by programming. Each variable must be entered in the program. In our technologicalprocess, humidity, temperature and additional luminosity indicators are countered. Different sensors are used to monitor these indicators. The number of these sensors is selected depending on the size of the greenhouse and the main indicators [10].

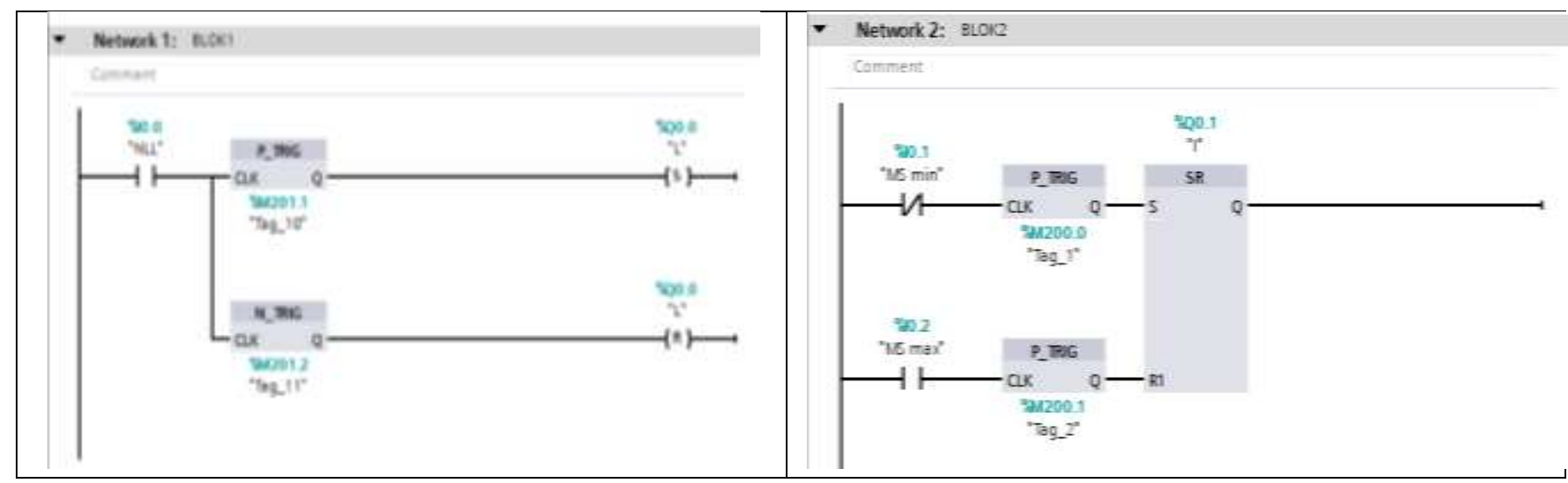




\section{Implementation of Automation System in Production in Hydroponic Green Feed}

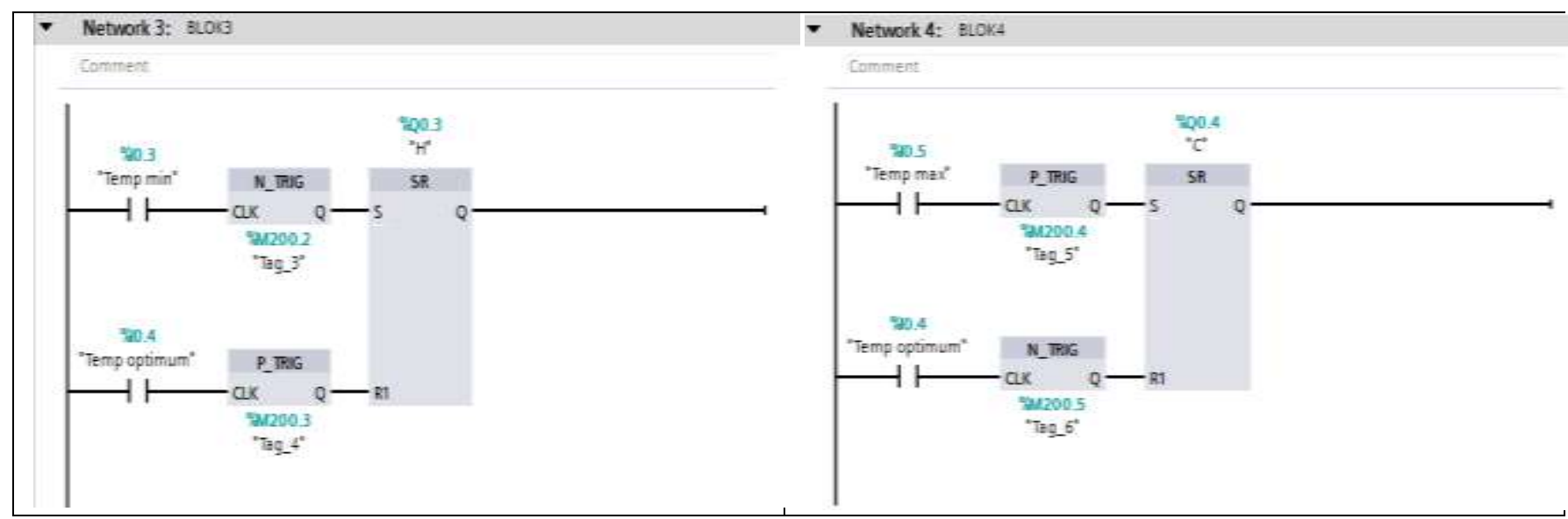

Fig. 7. Electronic picture: Part of a program written in the LD programming language

The program for controlling the technological process of growing green feed was written in the LD programming language for S7-1200 controllers(Fig. 7).

Consider the parameters of a technological process controlled in a program, for example, the theory of temperature control.

The paper describes the law of temperature regulation - positional. In this method, the heater is supplied with full power until the specified temperature is reached, after which the power supply stops. Despite this, the heated heater continues to give heat and the temperature of the object continues to increase for some time, which leads to overheating, sometimes significant. With the subsequent cooling of the object, upon reaching the set temperature value, the heater again full power is supplied. The heater first warms itself up, then the surrounding areas of the object, and thus cooling will continue until the heat wave reaches the temperature sensor. Consequently, the real temperature may be well below the set value. Thus, under the positional law of regulation, significant temperature fluctuations around a given value are possible.

This disadvantage can be reduced or even eliminated altogether by applying proportionally the integral-differential law of regulation (PID law). PID involves reducing the power supplied to the heater as the temperature of the object approaches the set temperature. In addition, in the steady mode of regulation according to piD law is the amount of thermal power necessary to compensate for heat loss and maintain a given temperature.

Proportional - integral-differential control law provides a significantly higher accuracy of temperature maintenance than positional [12]. The power N, which must be emitted by the heater, expressed as a percentage of its maximum power, is calculated by the formula:

$$
\mathrm{N}=\frac{100}{\mathrm{Kp}}\left(\Delta \mathrm{T}+\frac{1}{\mathrm{Ki}} \int_{0}^{1} \Delta \mathrm{Tdt}-\mathrm{Kd} \frac{\mathrm{dT}}{\mathrm{dt}}\right) .
$$

Where are the proportional, integral and differential coefficients of regulation respectively (PID coefficients).Kp, Ki, Kd

The first term in the expression (proportional component) is directly proportional to the "non-viscosity" - the difference in the temperature setting $\Delta \mathrm{T}=\mathrm{T}_{\mathrm{us}}-\mathrm{T}$ Twhiskers and the measured temperature value T.Its meaning is that with "nonviscosity" (in ${ }^{\circ} \mathrm{C}$ ), the regulator will begin to reduce power. $\Delta \mathrm{T}=\mathrm{Kp}$

The second component in the steady state of regulation is equal to the amount of thermal power necessary to compensate for heat losses at $\Delta T=0$.

The third component is proportional to the rate of change of temperature with the reverse sign and should prevent abrupt changes in the temperature of the object (differential component). 


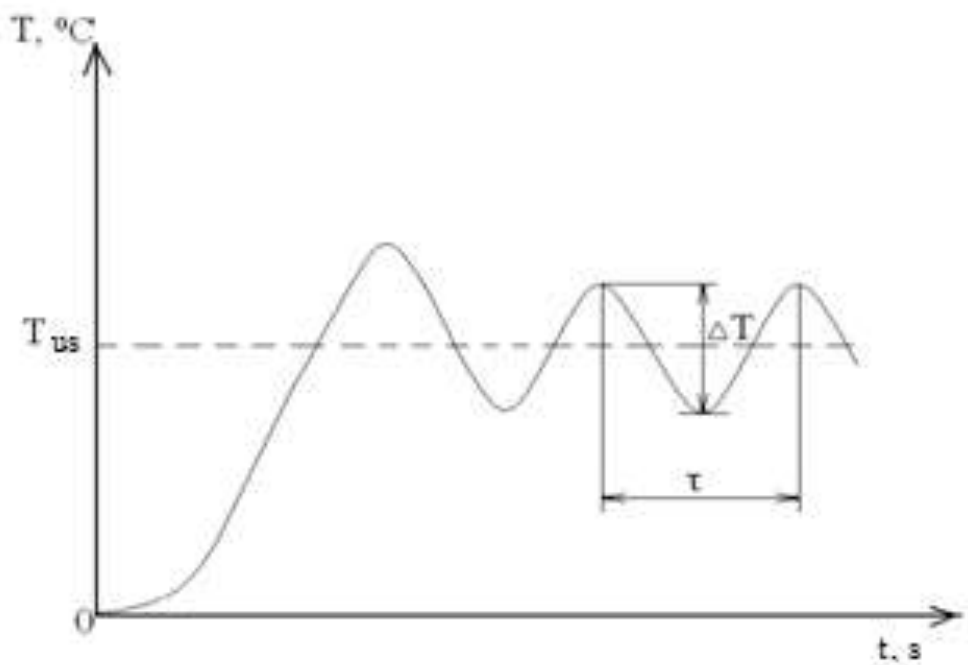

Fig 8. Temperature transient process

In order to achieve a high quality of temperature control, it is necessary to properly configure the regulator - set three coefficients. PiD regulation coefficients in Thermodate devices can be found automatically when starting the auto-tuning mode, but can be set by the equipment adjuster in the manual adjustment mode of the device. Finding and setting up coefficients requires experience from the user. Recommendations for configuration are given in special technical and scientific literature. Here we give options for adjusting the PID of the law of regulation according to the Ziegler-Nicholson method[11].

A convenient method of finding PID coefficients for medium-sized electric furnaces.

1. Assign a $\mathrm{T}_{\mathrm{us}}$ equal to the control temperature (or $0.7 \mathrm{~T}_{\mathrm{us}}$ if overheating during setup is undesirable, and it may be significant).

2. Enable positional regulation mode.

3. In steady state temperature fluctuations, measure the period $\tau$ of temperature fluctuations (the time between adjacent maximum or minimum temperature values). Also measure the full range of temperature fluctuations (the difference in maximum and minimum temperature values). $\Delta \mathrm{T}=\mathrm{T}_{\max }-\mathrm{T}_{\min }$

4. Set the values of the coefficients $\mathrm{Kp}, \mathrm{Ki}, \mathrm{Kd}$ in accordance with the table. The parameter "Restriction of PID" or "Zone" (if it is in the device) to make equal to Kp.

\begin{tabular}{|l|l|l|l|}
\hline Type of regulation & $\begin{array}{l}\text { Proportional } \\
\text { coefficient Kp }\end{array}$ & $\begin{array}{l}\text { Integral } \\
\text { coefficient Ki }\end{array}$ & $\begin{array}{l}\text { Differential } \\
\text { coefficient Kd }\end{array}$ \\
\hline P only & $1.4 \cdot \Delta \mathrm{T}$ & Off & Off \\
\hline $\mathrm{P}+\mathrm{I}$ & $1.6 \cdot \Delta \mathrm{T}$ & $2.4 \cdot \tau$ & Off \\
\hline $\mathrm{P}+\mathrm{I}+\mathrm{D}$ & $1.2 \cdot \Delta \mathrm{T}$ & $1.5 \cdot \tau$ & $0.2 \cdot \tau$ \\
\hline
\end{tabular}

\section{CONCLUSION}

In conclusion, it can be noted that the developed hydroponic green diet contains all the necessary substances rich in vitamins and minerals, natural, vitaminized greens, easily digestible by any types of omnivorous, herbivorous animals and completely replenishes the diet of animals with nutritious things and mineral additives [13].

The design of hydroponic systems for growing green feeds is distinguished by its technology, which does not require special skills or special training. A distinctive feature of this installationis thatit is fully automatedand, which practically eliminates the human factor. With the help of a computer, the microclimate, time, abundance of watering of each crop is controlled separately [14,15].

And the use antitechnology allows you to study in more detail the system of its preparation using an automated system using automation elements.

The considered theoretical features of the use of automaticadjustment regulators, then in the real case, Thermodat devices with PID regulation allow you to choose PID coefficients in the mode of automatic setting.

Thermodate devices with archive and interface can significantly simplify this process. The computer program allows you to organize an automatic survey of the device, observe and print out the temperature graph. Another option for using the archive memory of Thermodat devices: the measured temperature is recorded in the built-in Flash memory of the device with reference 


\section{Implementation of Automation System in Production in Hydroponic Green Feed}

to real time, then "downloaded" to the computer via the interface, where it is presented in the form of tables or graphs for further processing.

\section{REFERENCES}

1) Naumov, Jurij; Pugač, Igor' (2019). Problems and prospects ofanimal husbandry in Uzbekistan. Discussion Paper, No.188. Leibniz Institute of Agricultural. Development in Transition Economies (IAMO), Halle (Saale), http://nbnresolving.de/urn:nbn:de:gbv:3:2-112940.

2) V.I.Volgin, L.V.Romanenko, P.N.Prokhorenko, Z.L.Fedorova, E.A.Korochkina. Full feedingof dairycattle is the basis for the realization of thegetic potential of productivity //. -M.: RAS, 2018.-260 p.

3) Butler,W.R. Energy balancerelationshipswithfol-licular development,Ovulationand fertility in post-par-tumdairy cows //Livest.Prod.Sci.. -2003.-vol.83.-p.211-218.

4) Abrahamyan A.C. To the issue of clarifying the nutritional value of bulky feeds and the use of reference data in the preparation of rations / Mat. Int. scientific- practical. Conf. - Dubrovitsy: GNU VIZH. - 2012. - Pp. 120-123.

5) Rajkumar G., Dipu M.T., Lalu K., Shyama K. and Banakar P.S. Evaluation of hydroponics fodder as a partial feed substitute in the ration of crossbred calves. Indian Journal of Animal Research. 2018, V. 52, N 12, pp. 1809-1813.

6) Matserushka A.R., Belik N.I., Stanishevskaya O.I. Biological value of hydroponic green feed for cows . / Proceedings of the St. Petersburg State Agrarian University. - 2016. - No 45. - Pp. 118-123.

7) Elizarova T.I., Esauova L.A. Improvement of hydroponic technology of green feed production . - 2013. - № 10. pp. 1115.

8) V.A. Kostyuchenko, V.M. Bulgakov, N.A. Sviren, V.V. Driga. Agromexanical substantiation of machines for the production of hydroponic green feed: Monograph. -Kirovograd: KOD, 2010. - 320 p.

9) Kalandarov P.I., Mukimov Z.M., Logunova O.S. Anaiysis of hudrothermanal feafures of grain and instrument desulphurization of moisture control. Technical Science and Innovation. 2020. № 1. Pp. 117-123.

10) Kalandarov P.I., Logunova O.S., Andreev S.M. Nauchnye osnovy vlagometry. Monography / Tashkent, 2021.174 p.

11) Zorin S.V. PID-law of regulation. Methods of finding PID coefficients. Control Systems. 2017. Pp. 1-5.

12) Kalandarov P.I., Iskandarov B.P. Physicochemical measurements: measurement of the moisture content of brown coal from the Angrensk deposit and problems of metrological assurance. Measurement Techniques. 2012. T. 55. № 7. Pp. 845848.

13) Kalandarov P.I., Iskandarov B.P. P.Moisture control ribs for automation of technological processes of agro-industrial complex production. Automated technologies and production. 2013. № 5. Pp. 179-184.

14) Iskandarov B.P., Kalandarov P.I. An analysis of the effect of interfering factors on the results of measurements of the moisture content of a material at high frequenciesMeasurement Techniques. 2013. T. 56. № 7. Pp. 827-830.

15) Kalandarov P.I., Mukimov Z.M. Moisturecontrol in hydrothermal treatment of grain and products of its processing. Devices. 2020. № 11 (245). Pp. 16-21. 